\title{
Identification of posterior visual pathway lesions and MRI burden in people with Multiple Sclerosis
}

\author{
Tareef S. Daqqaq, MD, Fachartz.
}

\begin{abstract}
الأهداف : تحدد هذه المراجعة بشكل منهجي آفات المسار البصري المباري

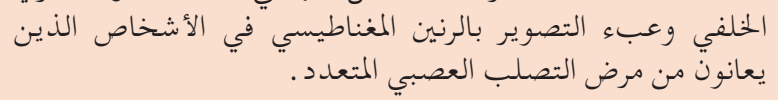

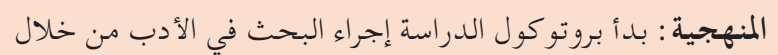

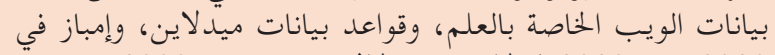


2019

النتائج : وقد قدمت هذه المراجعة تدابير موجزة إذا كانت متعلقة إلماني

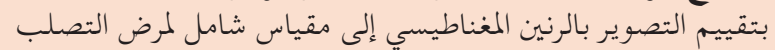

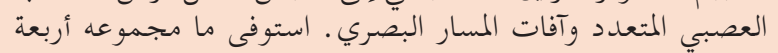

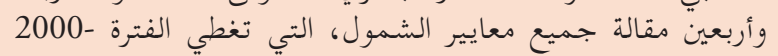

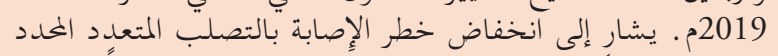

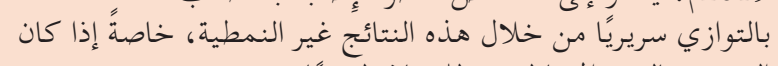

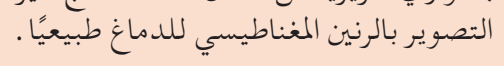
الحلاصة : حدد المرضى عيوبًا في جودة الحياة المرتبطة بالرؤية بسبب الفبرة



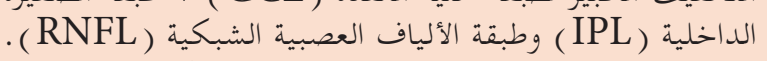

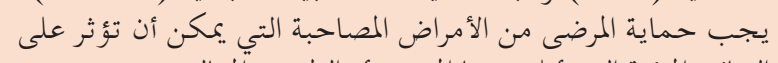
النتائج المرئية التي أبلغ عنها المريض أو الطبيب المعالج.

Objectives: This review systematically identifies posterior visual pathway lesions and MRI burden in people with multiple sclerosis (MS).

Methods: The articles were searched through Web of Science, Medline, and Embase databases on January 2020, for English language articles from 2000 to 2019.

Results: This review presents summary measures if related to MRI assessment to an overall measure of MS and visual pathway lesions. A total of 44 articles fulfilled all inclusion criteria, covering the period 2000-2019. Different atypical outcomes reveal a low risk for subsequent clinically predefined MS development, specifically in the presence of normal brain MRI. Several impairments related to quality of life have been identified as a result of the effect of
\end{abstract}

retinal nerve fiber layer, ganglion cell layer, and inner plexiform layer.

Conclusion: The afferent visual system in MS offers unique accessibility and structure-related functions with further understanding offered by electrophysiology, considering vision as a useful framework for examining new multiple sclerosis therapies.

Neurosciences 2021; Vol. 26 (2): 120-127 doi: 10.17712/nsj.2021.2. 20200048

From the Department of Radiology, College of Medicine, Taibah University, Madinah, Kingdom of Saudi Arabia.

Received 2nd October 2020. Accepted 1st January 2021.

Address correspondence and reprint request to: Dr. Tareef S. Daqqaq, Department of Radiology, College of Medicine, Taibah University, Madinah, Kingdom of Saudi Arabia.

E-mail:dr.tareef@gmail.com

ORCID ID: https://orcid.org/0000-0002-1479-0897

$M$ ultiple sclerosis (MS) is an unidentifiable disease of the central nervous system (CNS) that interrupts the flow of information throughout the brain and between the brain and the spinal cord. It is classified by both axonal degeneration and inflammation. Visual deficits are regular, and optic neuritis $(\mathrm{ON})$ is the earlier indication in approximately $20 \%$ of the patients experiencing MS. Multiple lesions are not experienced by optic neuritis patients as it is often determined among two-third of the patients. ${ }^{1,2}$ The $\mathrm{ON}$ influences patients with MS during their disease course at some point. Differentiation of acute episodes is essential for treatment selection and additional patient management with respect to MS-related optic neuritis. ${ }^{3}$ Intereye difference thresholds might be beneficial to develop the occurrence of symptomatic and asymptomatic ON lesions in MS and can be beneficial in the diagnostic procedure. ${ }^{4}$ The visual system is highly vulnerable to MS associated damage. Visual disturbances are recurrent and cause extreme disability, but imaging has remained challenging because of technical limitations 
with respect to the visual pathway posterior to the optic chiasm as compared to the optic radiation (OR). ${ }^{5}$ The visual pathway is typically involved in MS, even in its preliminary stages such as in its clinical episodes of ON. Long-term structural damage throughout the retina and $\mathrm{OR}$ induced a single history of $\mathrm{ON}$, which recommend both anterograde and retrograde neuroaxonal degeneration. ${ }^{6}$

The most recurrent affected white matter pathway is represented from the afferent visual pathway in MS and neuromyelitis optics spectrum disorders. Non-overt brain tissue or microstructural and pathological procedure quantification can be revealed through diffusion tensor imaging (DTI). The reconstruction of major white matter fiber tracts can be facilitated through DTI, which allow the evaluation of damagedysfunction and structure-function associations. ${ }^{7}$

Optic neuritis was recently proposed as in vivo models in order to examine the pathophysiology of tissue damage and repair in MS with the visual pathways, and clinical manifestation that are agreeable to examine with different visual functional and imaging, and structural techniques. ${ }^{8}$ OR lesions cause retrograde transneuronal degeneration, which might play an essential role in progressive retinal nerve fiber layer loss. Additionally, it has been observed that the disease-associated neurodegenerative modifications in the retina instigate much earlier as compared to the clinical diagnosis of MS. ${ }^{?}$

An important region of disease activity in MS is the visual pathway. Optic neuritis is an onset symptom, and almost $50 \%$ of MS patients have an occurrence of ON in their lifetime. ${ }^{10}$ Sub-clinical ON was also pre-defined and well-established, regardless of any effect of overt attacks. ${ }^{11}$ However, there is lack of evidence regarding the level of MS-associated impairments in the optic tracts with the development of $\mathrm{ON}$ continuation after preliminary decussation. ${ }^{12}$ Further information should be provided regarding the role of the visual platforms in MS visual dysfunction. Such information will allow studying optic tracts, which extend from the optic chiasm to the lateral geniculate nucleus, considering the rarity of focal lesion in the optic tract. ${ }^{13}$

Previous studies have found that neurodegeneration and neuroinflammation could drive to an interaction of several aspects of the visual pathway such as retinal

Disclosure. The Authors have no conflict of interests and the work was not supported or funded by any drug company. nerve axonal degeneration, intraretinal inflammation, pathological changes in the optic tract, retinal neurodegeneration, the visual cortex, and the optic radiation. ${ }^{14-19}$ However, sensitive and vision-specific outcome measures were scarcely reported in MS clinical trials. The identification of low-contrast letter acuity (LCLA) is considered as a dominant actor to measure visual drawbacks in MS. It is related particularly with quality of life measures, offering evidence on clinical importance and with the structural integrity of the retina for performing optical coherence tomography. ${ }^{20}$

These factors led to collect information about visual drawbacks in ON and MS. The rapid availability facilitates the development of the visual platform, an advantageous model system to support inflammatory and neurodegenerative mechanisms in the Central Nervous System (CNS) for examining novel agents for detecting and repairing MS, considering further advancement of structural information and electrophysiological measures. ${ }^{21-23}$ The relationship between visual dysfunction and MRI is not fully understood, but impairments assessed within whitematter optic tracts have indicated higher associations between spinal cord, corpus callosum, behavioral dysfunction, and corticospinal tract. ${ }^{24-26}$

This review systematically identifies the posterior visual pathway lesions and the MRI burden in people with MS. We systematically reviewed visual lesions, MRI burden, visual pathways, and MS via randomized controlled trials. This review further presents the role of MRI in identifying posterior visual pathway lesions in MS patients and offers mechanisms that assist to understand the importance of a model vision for assessing consequences in the field of therapy

Methods. PRISMA guidelines were used for the design of the systematic review and manuscript elements. $^{27}$

Data collection, search strategy, and protocol. Prior to the literature search, we developed the protocol for this paper. The databases Web of Science, Medline, and Embase were searched on January 11, 2020, for English language articles, with a restriction of 20 years from 2000 to 2019. Review articles were excluded from the search process. For narrowing the search process, Multiple Sclerosis, the American Journal of Neuroradiology, and Archives of the journals were further hand-searched for appropriate articles published within these 20 years, using the following search terms: 'multiple sclerosis', 'magnetic resonance imaging', 'posterior visual pathway lesions', 'vision', and 'visual outcomes', as well as the abbreviations of these key terms. 
Eligibility criteria and study selection. Two researchers initially screened the abstracts. In addition, the first researcher evaluated the eligibility criteria for retrieving published papers in a standardized manner. The consent of a second researcher was taken over the eligibility criteria process to prepare a list of final articles.

The following eligibility criteria were considered: publications reporting MS outcomes in both adults and children were targeted, publications reporting a relationship with MRI burden or posterior visual pathway lesions, radiological outcomes for visual pathway lesions as measures of MRI. Articles were excluded if MRI burden was only related to changes in the visual outcome or if reporting secondary or exploratory analyses. The researcher used baseline crosssectional studies for investigating findings related to both cross-sectional and longitudinal designs. The researcher also applied a conventional approach to include only recent and relevant articles when overlapping with cohort studies. No meta-analysis was conducted in this systematic review; therefore, information about the overall effect on the relationship between any of the primary outcomes was not searched and presented.

Data collection. A standardized form was used by the primary researcher to extract the data with information on (1) MRI outcomes, (2) characteristics of the participants (age, gender, and visual analysis phenotypes, (3) multiple sclerosis lesions, (4) MRI assessment including blinding and training of investigators, software tools used, and (5) statistical analysis methods. A study quality assessment tool was developed in this systematic review on the basis of the STROBE guidelines to evaluate the risk of bias in each published article. ${ }^{28}$

Synthesis of results and summary measures. This review presents summary measures if related to MRI assessment to an overall measure of MS and visual pathway lesions. Both adjusted and unadjusted measures were extracted for determining adjusted outcomes for possible confounding clinical parameters. The difference or correlation parameters in MRI burden were considered as summary measures between cohorts defined by the MS status.

Risk of bias across studies. A stated primary aim was required for the eligibility criteria to assess the relationship between visual pathway lesions, MRI burden, and MS, so that this review could reduce the reporting bias effect via post-hoc examinations. This review documented analyses that were explained regardless of any results being provided throughout the included studies.

Results. The initial literature search extracted a total of 2,504 published articles. Figure 1 shows the duplicates extracted from this initial literature search $(\mathrm{n}=1,560)$. The publication rate was documented with respect to year-by-year publications in the preliminary search list. No additional publications were included after searching manually from journal databases. In total, 125 articles were retrieved after the review of the abstracts. Of these, 81 articles were correspondingly excluded, most frequently $(30 / 81=37 \%)$ due to irrelevant study aim. A total of 44 articles fulfilled all inclusion criteria, ${ }^{29-74}$ covering the period 2000-2019.

Quality appraisal and risk of bias. The researcher observed a range of study-related quality scores and provided complete reporting for outcome parameters as well as inclusion criteria among individual aspects. However, overall reporting of likely study size rationale, confounding factors, and measurement methodology was not provided by any study extracted.

Relationship between MS and ON. Unilateral ON often reaches a nadir throughout 2 weeks in adults, with visual impairments related to loss emerged in a short-term period and often linked with peri-orbital pain. ${ }^{29}$ Although complete loss is uncommon, decline in high-contrast visual acuity (HCVA) varies from minimal to severe. A comparative afferent pupillary defect in the affected eye was explained by typical evaluation because of reduced visual acuity, resulting from central visual field depression. The relationship between color vision and LCLA was more significantly influenced than HCVA. The optic disc is emerged in the majority of adult patients throughout the acute phase on direct ophthalmoscopy with ON. On the contrary, subclinical disc edema was revealed in many of the impacted eyes. ${ }^{30}$ The swelling of the optic disc is usually mild when visible, regardless of evidence of macular exudates or hemorrhages. A low risk for parallel clinically definite multiple sclerosis development is indicated through such atypical findings, particularly if the brain MRI is normal. ${ }^{31-33}$ Vision improves within 1 month just after acute optic neuritis follows visual symptoms.

The majority of patients have quality of life impairments related to vision pathways because of the retinal nerve fiber layer (RNFL), ganglion cell (GCL), and inner plexiform layer (IPL). ${ }^{34}$ The median loss of peri-papillary RNFL is $20-40 \%$ with in 3 and 6 months with most thinning. ${ }^{35-37}$ A previous study has revealed that significant retinal damage and vision loss are caused by $\mathrm{ON}$ regardless of the underlying disease. Soelberg et al. ${ }^{38}$ report that ganglion cell and inner plexiform layer (GCIP) loss damage initiates close to clinical onset. The significance of OCT in monitoring acute $\mathrm{ON}$ is supported by the relationship between vision support and OCT. Eyes suffering damage from optic neuritis 


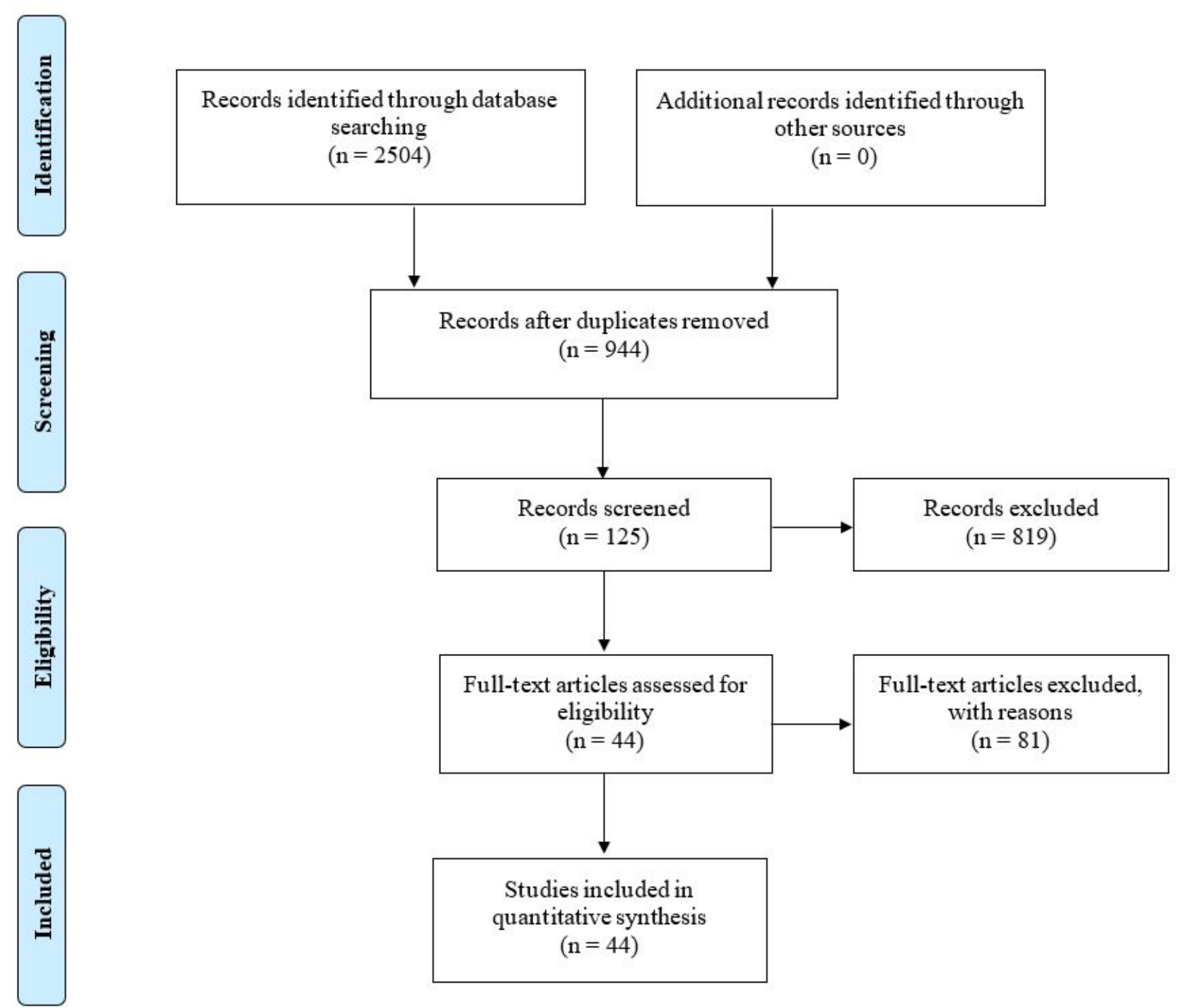

Figure 1 - PRISMA flowchart showing articles retrieved at each stage.

are substantially identified by inter-ocular GCIP as compared to visual acuity loss, absolute GCIP, or visual fields. Ganglion cell loss should be prevented through effective international options. ${ }^{39}$

With severe visual drawbacks, $10-15 \%$ of patients are prone to have severe RNFL loss. ${ }^{40}$ Two small studies followed a plasma exchange course among patients with poor vision and optic neuritis. ${ }^{41,42}$ Previous clinical trials reported the examination of intravenous immunoglobulin for ON with poor visual recovery. ${ }^{43,44}$ This unidentified need for optic neuritis treatment makes $\mathrm{ON}$ an appropriate mechanism system, along with the structure-function correlations and the wider range of available functional predictors for the testing of new neuro-protection therapies and multiple sclerosis repairment.

$M S$ indicators and retinal outcomes. Transient visual impairment was experienced by subjects reported with MS or ON, associated with an increase in body temperature. ${ }^{45}$ This symptom has been caused by a temporary limitation to conduct demyelinated axons in the afferent visual pathways. Other sensory and motor pathways can be affected by a similar phenomenon. Considering $\mathrm{ON}$, there might be limited motion perception, despite of static parameters of visual pathways. In functional MRI, a continued discrepancy has been associated with the Pulfrich phenomenon for associated tasks that require motion perception. ${ }^{46}$ 
A delayed latency response is developed in optic neuritis, which is linked with time-constrained binocular perception improvement. ${ }^{47}$ It suggests an adaptive cortical response for improving input synchronicity and, therefore, assists binocular vision. Patients with MS were reported with binocular inhibition and acute unilateral ON history. ${ }^{48}$ Similarly reported in post-mortem specimens of patients with MS, retinal layers impairment has been noticed other than the RNFL, where ganglion cell loss displayed in $79 \%$ of the eyes and $40 \%$ exhibited in amacrine loss and bipolar cell loss in the inner nuclear layer. ${ }^{49}$ Such outcomes have been supported by optical coherence tomography (OCT), explaining GCL + IPL thinning and are related with declines in vision-specific quality of life and visual function. ${ }^{50,51}$

Clinical measures and general images of MS disease activity and severity were associated with retinal outcomes. ${ }^{52,53}$ Microcystic macular oedema or thickening of the inner nuclear layer were reported in approximately $5 \%$ of patients with initial MS. ${ }^{54,55}$ Also, ON related with other inflammatory disorders resulted in inner nuclear layer thickening and microcystic macular edema. ${ }^{56,57}$ In addition, $\mathrm{ON}$ is associated with inflammatory disease activity in MS considering the presence of gadolinium enhancing lesions and T2 lesions on brand MRI. ${ }^{55}$ These observations indicate that the inflammatory process is not restricted to myelinated CNS structures in multiple sclerosis as the retinal layers do not comprise myelin. However, the occurrence of microcystic macular edema revealed other platforms in non-inflammatory ON..$^{58}$ Retinal layers and macular thinning on OCT were relatively preserved among $10 \%$ of the patients. ${ }^{59}$ The existence of a primary retinal pathology in MS as suggested in Saidha et $\mathrm{al}^{55}$ is still controversial. According to Brandt et $\mathrm{a}^{60}$ these outcomes will have a significant effect on patient counselling and the understanding of MS disease heterogeneity and pathogenesis.

Discussion. Acute inflammatory demyelination is represented through acute optic neuritis elsewhere in the CNS and can therefore assist as a more globalized framework for repair and neuroprotection. In parallel and non-invasive elements, clinical functions can be evaluated with the assistance of $\mathrm{ON}$, specifically in vivo parameters of structure and electrophysiology. In addition, visual function measures are more sensitive, quantitative, and reliable based on functional measures of other anatomic CNS sites. It was essential that clinical trials emphasized acute optic neuritis, showing adequately stringent eligibility criteria for ensuring an exact diagnosis and avoiding recruiting patients with other causes of visual loss or forms of optic neuropathy. Likewise, participants should be protected with comorbidities that can influence patient-reported outcomes.

The effectiveness of a central OCT reading center for clinical trials is underscored by longitudinal studies of OCT. ${ }^{75}$ For training sites, a vital OCT reading platform is used for obtaining standardized image procedures, which is considered a standard approach in MS clinical trials. Automated segmentation is highly relevant when performed by experienced raters with manual correction of macular OCT scans and can therefore be implemented in multicenter settings. ${ }^{76}$

Computerized retinal segmentation software and developed case report forms, parallel to a central MRI reading center, are also deployed. Such multi-center studies have required validated and clear quality control tools. ${ }^{77}$ Cruz-Herranz et al $^{78}$ have offered recommendations to uniformly and vigorously report quantitative OCT studies to report research in other biomedical realms. Class IV evidence is represented through the recommendations originated from expert consensus; these studies should be regularly balanced for new practices and insights.

Patients should be protected with comorbidities that can influence patient-reported or clinician-assessed visual outcomes. In recent times, the understanding of vision in MS has significantly expanded based on evidence presented in a systematic review. ${ }^{79}$ The predefined and validated network of examiners can benefit from current and future studies. However, there is still a need to bridge this gap in several areas such as inter-relationship measures assessment, fluid-based biomarker validation, and application and development of imaging and electrophysiological techniques both in clinical and randomized controlled trials.

In particular, clinical measures will be required to address visual limitations related to prediction and timing for generally measuring neurologic disability. It is important to predict the clinical significance of visual pathways based on patient-related outcomes to approve the policies proposed by regulatory agencies. Furthermore, assessment of their optimum application can be performed through normative values, specifically in clinical trials and clinical practice. Lastly, the development of practical methods should be based on the assessment of eye movements in clinical trials. It will be important to measure the capacity of repairing and protecting the nervous system, specifically related to visual function, visual pathway structure, electrophysiology, and quality of life. Vision is among 
the most important functions from the perspective of MS patients, ${ }^{80}$ and should be a key patient reported outcome in MS trials. ${ }^{81}$ In addition, there will be continual dependency on structural consequences of MRI and OCT for documenting advantages to reduce axonal and neuronal degeneration or to improve tissue repair. In both modalities, technological advancements will provide prognostic markets for monitoring pathology in the anterior visual pathways and therapy modification.

Acknowledgements. The authors would like to thank Proof-Reading-Service.com (www.proof-reading-service.com) for English language editing. Further, this research holds no conflict of interest and is not funded through any source.

\section{References}

1. Britze J, Frederiksen JL. Optical coherence tomography in multiple sclerosis. Eye (Lond) 2018; 32: 884-888.

2. Petzold A, de Boer JF, Schippling S, Vermersch P, Kardon R, Green A, et al. Optical coherence tomography in multiple sclerosis: a systematic review and meta-analysis. Lancet Neurol 2010; 9: 921-932.

3. Petzold A, Wattjes MP, Costello F, Flores-Rivera J, Fraser CL, Fujihara K, et al. The investigation of acute optic neuritis: a review and proposed protocol. Nat Rev Neurol 2014; 10: 447.

4. Nolan-Kenney RC, Liu M, Akhand O, Calabresi PA, Paul F, Petzold A, et al. Optimal intereye difference thresholds by optical coherence tomography in multiple sclerosis: An an international study. Ann Neurol 2019; 85: 618-629

5. Sinnecker T, Oberwahrenbrock T, Metz I, Zimmermann $\mathrm{H}$, Pfueller CF, Harms L, et al. Optic radiation damage in multiple sclerosis is associated with visual dysfunction and retinal thinning-an ultrahigh-field MR pilot study. Eur Radiol 2015; 25: 122-131.

6. Pawlitzki M, Horbrügger M, Loewe K, Kaufmann J, Opfer $\mathrm{R}$, Wagner M, et al. MS optic neuritis-induced long-term structural changes within the visual pathway. Neurol Neuroimmunol Neuroinflamm 2020; 7: 7.

7. Kuchling J, Brandt AU, Paul F, Scheel M. Diffusion tensor imaging for multilevel assessment of the visual pathway: possibilities for personalized outcome prediction in autoimmune disorders of the central nervous system. EPMA J 2017; 8: 279-294

8. Backner Y, Kuchling J, Massarwa S, Oberwahrenbrock T, Finke C, Bellmann-Strobl J, et al. Anatomical wiring and functional networking changes in the visual system following optic neuritis. JAMA Neurol 2018; 75: 287-295.

9. Klistorner A, Graham EC, Yiannikas C, Barnett M, Parratt J, Garrick R, et al. Progression of retinal ganglion cell loss in multiple sclerosis is associated with new lesions in the optic radiations. Eur J Neurol 2017; 24: 1392-1398.

10. Balcer LJ. Optic neuritis. N Engl J Med 2006; 354: 1273-1280.

11. Sisto D, Trojano M, Vetrugno M, Trabucco T, Iliceto G, Sborgia C. Subclinical visual involvement in multiple sclerosis: a study by MRI, VEPs, frequency-doubling perimetry, standard perimetry, and contrast sensitivity. Invest Ophthalmol Vis Sci 2005; 46: 1264-168.
12. Dasenbrock HH, Smith SA, Ozturk A, Farrell SK, Calabresi PA, Reich DS. Diffusion tensor imaging of the optic tracts in multiple sclerosis: association with retinal thinning and visual disability. J Neuroimaging 2011; 21: e41-e49.

13. Kale N. Optic neuritis as an early sign of multiple sclerosis. Eye Brain 2016; 8: 195-202.

14. Green AJ, McQuaid S, Hauser SL, Allen IV, Lyness R. Ocular pathology in multiple sclerosis: retinal atrophy and inflammation irrespective of disease duration. Brain 2010; 133: 1591-1601.

15. Gordon-Lipkin E, Chodkowski B, Reich DS, Smith SA, Pulicken M, Balcer LJ, et al. Retinal nerve fiber layer is associated with brain atrophy in multiple sclerosis. Neurology 2007; 69: 1603-1609.

16. Evangelou N, Konz D, Esiri MM, Smith S, Palace J, Matthews PM. Size-selective neuronal changes in the anterior optic pathways suggest a differential susceptibility to injury in multiple sclerosis. Brain 2001; 124: 1813-1820.

17. Sepulcre J, Goñi J, Masdeu JC, Bejarano B, de Mendizábal NV, Toledo JB, et al. Contribution of white matter lesions to gray matter atrophy in multiple sclerosis: evidence from voxel-based analysis of T1 lesions in the visual pathway. Arch Neurol 2009; 66: 173-179.

18. Audoin B, Fernando KT, Swanton JK, Thompson AJ, Plant GT, Miller DH. Selective magnetization transfer ratio decreases in the visual cortex following optic neuritis. Brain 2006; 129: 1031-1039.

19. Pfueller CF, Paul F. Imaging the visual pathway in neuromyelitis optica. Mult Scler Int 2011; 2011: 869814.

20. Balcer LJ, Miller DH, Reingold SC, Cohen JA. Vision and vision-related outcome measures in multiple sclerosis. Brain 2014; 138: 11-27.

21. Frohman EM, Costello F, Stüve O, Calabresi P, Miller DH, Hickman SJ, et al. Modeling axonal degeneration within the anterior visual system: implications for demonstrating neuroprotection in multiple sclerosis. Arch Neurol 2008; 65: 26-35.

22. Frohman EM, Fujimoto JG, Frohman TC, Calabresi PA, Cutter G, Balcer LJ. Optical coherence tomography: a window into the mechanisms of multiple sclerosis. Nat Clin Pract Neurol 2008; 4: 664-675.

23. Barkhof $\mathrm{F}$. The clinico-radiological paradox in multiple sclerosis revisited. Curr Opin Neurol 2002; 15: 239-245.

24. Rovaris M, Filippi M. Diffusion tensor MRI in multiple sclerosis. J Neuroimaging 2007; 17: S27-S30.

25. Fox RJ. Picturing multiple sclerosis: conventional and diffusion tensor imaging. InSeminars in neurology 2008; 4: 453-466.

26. Reich DS, Zackowski KM, Gordon-Lipkin EM, Smith SA, Chodkowski BA, Cutter GR, et al. Corticospinal tract abnormalities are associated with weakness in multiple sclerosis. AJNR Am J Neuroradiol 2008; 29: 333-339.

27. Moher D, Liberati A, Tetzlaff J, Altman DG, Prisma Group. Preferred reporting items for systematic reviews and metaanalyses: the PRISMA statement. PLoS Med 2009; 6: e1000097.

28. Von Elm E, Altman DG, Egger M, Pocock SJ, Gøtzsche PC, Vandenbroucke JP. The Strengthening the Reporting of Observational Studies in Epidemiology (STROBE) statement: guidelines for reporting observational studies. Ann Intern Med 2007; 147: 573-577. 
29. Toosy AT, Mason DF, Miller DH. Optic neuritis. Lancet Neurol 2014; 13: 83-99.

30. Kupersmith MJ. Neuro-vascular neuro-ophthalmology. Springer Science \& Business Media; 2012.

31. Optic Neuritis Study Group. Visual function more than 10 years after optic neuritis: experience of the optic neuritis treatment trial. Am J Ophthalmol 2004; 137: 77-83.

32. Optic Neuritis Study Group. Multiple sclerosis risk after optic neuritis: final optic neuritis treatment trial follow-up. Arch Neurol 2008; 65: 727-732.

33. Optic Neuritis Study Group. Visual function 15 years after optic neuritis: a final follow-up report from the Optic Neuritis Treatment Trial. Ophthalmology 2008; 115: 1079-1082.

34. Cole SR, Beck RW, Moke PS, Gal RL, Long DT. The Optic Neuritis Study Group. The National Eye Institute visual function questionnaire: experience of the ONTT. Optic Neuritis Treatment Trial. Invest Ophthalmol Vis Sci 2000; 41: 1017-1021.

35. Costello F, Coupland S, Hodge W, Lorello GR, Koroluk J, Pan YI, et al. Quantifying axonal loss after optic neuritis with optical coherence tomography. Ann Neurol 2006; 59: 963-969.

36. Costello F, Hodge W, Pan YI, Eggenberger E, Coupland S, Kardon RH. Tracking retinal nerve fiber layer loss after optic neuritis: a prospective study using optical coherence tomography. Mult Scler 2008; 14: 893-905.

37. Henderson AP, Altmann DR, Trip AS, Kallis C, Jones SJ, Schlottmann PG, et al. A serial study of retinal changes following optic neuritis with sample size estimates for acute neuroprotection trials. Brain 2010; 133: 2592-2602.

38. Soelberg K, Specovius S, Zimmermann HG, Grauslund J, Mehlsen JJ, Olesen C, et al. Optical coherence tomography in acute optic neuritis: A population-based study. Acta Neurol Scand 2018; 138: 566-573.

39. Brandt AU, Specovius S, Oberwahrenbrock T, Zimmermann HG, Paul F, Costello F. Frequent retinal ganglion cell damage after acute optic neuritis. Mult Scler Relat Disord 2018; 22: 141-147.

40. Costello F, Hodge W, Pan YI, Burton JM, Freedman MS, Stys PK, et al. Sex-specific differences in retinal nerve fiber layer thinning after acute optic neuritis. Neurology 2012; 79: 1866-1872.

41. Ruprecht K, Klinker E, Dintelmann T, Rieckmann P, Gold R. Plasma exchange for severe optic neuritis: treatment of 10 patients. Neurology 2004; 63: 1081-1083.

42. Roesner S, Appel R, Gbadamosi J, Martin R, Heesen C. Treatment of steroid-unresponsive optic neuritis with plasma exchange. Acta Neurol Scand 2012; 126: 103-108.

43. Noseworthy JH, O’brien PC, Petterson TM, Weis J, Stevens $\mathrm{L}$, Peterson WK, et al. A randomized trial of intravenous immunoglobulin in inflammatory demyelinating optic neuritis. Neurology 2001; 56: 1514-1522.

44. Tselis A, Perumal J, Caon C, Hreha S, Ching W, Din M, et al. Treatment of corticosteroid refractory optic neuritis in multiple sclerosis patients with intravenous immunoglobulin. Eur J Neurol 2008; 15: 1163-1167.

45. Fraser CL, Davagnanam I, Radon M, Plant GT. The time course and phenotype of Uhthoff phenomenon following optic neuritis. Mult Scler 2012; 18: 1042-1044.

46. Raz N, Dotan S, Benoliel T, Chokron S, Ben-Hur T, Levin N. Sustained motion perception deficit following optic neuritis: Behavioral and cortical evidence. Neurology 2011; 76: 2103-2111.
47. Raz N, Chokron S, Ben-Hur T, Levin N. Temporal reorganization to overcome monocular demyelination. Neurology 2013; 81: 702-709.

48. Pineles SL, Birch EE, Talman LS, Sackel DJ, Frohman EM, Calabresi PA, et al. One eye or two: a comparison of binocular and monocular low-contrast acuity testing in multiple sclerosis. Am J Ophthalmol 2011; 152: 133-140.

49. Martínez-Lapiscina EH, Fraga-Pumar E, Gabilondo I, Martínez-Heras E, Torres-Torres R, Ortiz-Pérez S, et al. The multiple sclerosis visual pathway cohort: understanding neurodegeneration in MS. BMC Res Notes 2014; 7: 910.

50. Syc SB, Saidha S, Newsome SD, Ratchford JN, Levy M, Ford ET, et al. Optical coherence tomography segmentation reveals ganglion cell layer pathology after optic neuritis. Brain 2011; 135: 521-533.

51. Walter SD, Ishikawa H, Galetta KM, Sakai RE, Feller DJ, Henderson SB, et al. Ganglion cell loss in relation to visual disability in multiple sclerosis. Ophthalmology 2012; 119: 1250-1257.

52. Ratchford JN, Saidha S, Sotirchos ES, Oh JA, Seigo MA, Eckstein C, et al. Active MS is associated with accelerated retinal ganglion cell/inner plexiform layer thinning. Neurology 2013; 80: 47-54.

53. Saidha S, Sotirchos ES, Oh J, Syc SB, Seigo MA, Shiee N, et al. Relationships between retinal axonal and neuronal measures and global central nervous system pathology in multiple sclerosis. JAMA Neurol 2013; 70: 34-43.

54. Gelfand JM, Goodin DS, Boscardin WJ, Nolan R, Cuneo A, Green AJ. Retinal axonal loss begins early in the course of multiple sclerosis and is similar between progressive phenotypes. PLoS One 2012; 7: e36847.

55. Saidha S, Sotirchos ES, Ibrahim MA, Crainiceanu CM, Gelfand JM, Sepah YJ, et al. Microcystic macular oedema, thickness of the inner nuclear layer of the retina, and disease characteristics in multiple sclerosis: a retrospective study. Lancet Neurol 2012; 11: 963-972.

56. Kaufhold F, Zimmermann H, Schneider E, Ruprecht K, Paul F, Oberwahrenbrock T, et al. Optic neuritis is associated with inner nuclear layer thickening and microcystic macular edema independently of multiple sclerosis. PloS one 2013; 8: e71145.

57. Brandt AU, Oberwahrenbrock T, Kadas EM, Lagrèze WA, Paul F. Dynamic formation of macular microcysts independent of vitreous traction changes. Neurology 2014; 83: 73-77.

58. Burggraaff MC, Trieu J, de Vries-Knoppert WA, Balk L, Petzold A. The clinical spectrum of microcystic macular edema. Invest Ophthalmol Vis Sci 2014; 55: 952-961.

59. Saidha S, Syc SB, Ibrahim MA, Eckstein C, Warner CV, Farrell $\mathrm{SK}$, et al. Primary retinal pathology in multiple sclerosis as detected by optical coherence tomography. Brain 2011; 134: 518-533.

60. Brandt AU, Oberwahrenbrock T, Ringelstein M, Young KL, Tiede M, Hartung HP, Martin R, Aktas O, Paul F, Schippling $\mathrm{S}$. Primary retinal pathology in multiple sclerosis as detected by optical coherence tomography. Brain 2011; 134: e193-e194.

61. Wu GF, Schwartz ED, Lei T, Souza A, Mishra S, Jacobs DA, et al. Relation of vision to global and regional brain MRI in multiple sclerosis. Neurology 2007; 69: 2128-2135.

62. Trip SA, Miller DH. Imaging in multiple sclerosis. J Neurol Neurosurg Psychiatry 2005; 76: iii11-iii18.

63. Kanamori A, Nakamura M, Escano MF, Seya R, Maeda H, Negi A. Evaluation of the glaucomatous damage on retinal nerve fiber layer thickness measured by optical coherence tomography. Am J Ophthalmol 2003; 135: 513-520. 
64. Kalincik T. Multiple sclerosis relapses: epidemiology, outcomes and management. A systematic review. Neuroepidemiology 2015; 44: 199-214.

65. Sepulcre J, Murie-Fernandez M, Salinas-Alaman A, GarcíaLayana A, Bejarano B, Villoslada P. Diagnostic accuracy of retinal abnormalities in predicting disease activity in MS. Neurology 2007; 68: 1488-1494.

66. Grazioli E, Zivadinov R, Weinstock-Guttman B, Lincoff N, Baier M, Wong JR, et al. Retinal nerve fiber layer thickness is associated with brain MRI outcomes in multiple sclerosis. $J$ Neurol Sci 2008; 268: 12-17.

67. Siger M, Dzięgielewski K, Jasek L, Bieniek M, Nicpan A, Nawrocki J, et al. Optical coherence tomography in multiple sclerosis. J Neurol 2008; 255: 1555-1560.

68. Dörr J, Wernecke KD, Bock M, Gaede G, Wuerfel JT, Pfueller $\mathrm{CF}$, et al. Association of retinal and macular damage with brain atrophy in multiple sclerosis. PLoS One 2011; 6: e18132.

69. Naismith RT, Piccio L, Lyons JA, Lauber J, Tutlam NT, Parks $\mathrm{BJ}$, et al. Rituximab add-on therapy for breakthrough relapsing multiple sclerosis: a 52-week phase II trial. Neurology 2010; 74: 1860-1867.

70. Smith SA, Williams ZR, Ratchford JN, Newsome SD, Farrell SK, Farrell JA, et al. Diffusion tensor imaging of the optic nerve in multiple sclerosis: association with retinal damage and visual disability. AJNR Am J Neuroradiol 2011; 32: 1662-1668.

71. Naismith RT, Xu J, Tutlam NT, Lancia S, Trinkaus K, Song SK, et al. Diffusion tensor imaging in acute optic neuropathies: predictor of clinical outcomes. Arch Neurol 2012; 69: 65-71.

72. Schmierer K, Scaravilli F, Altmann DR, Barker GJ, Miller DH. Magnetization transfer ratio and myelin in postmortem multiple sclerosis brain. Ann Neurol 2004; 56: 407-415.
73. Hickman SJ, Toosy AT, Jones SJ, Altmann DR, Miszkiel KA, MacManus DG, et al. A serial MRI study following optic nerve mean area in acute optic neuritis. Brain 2004; 127 : 2498-2505.

74. Sriram P, Graham SL, Wang C, Yiannikas C, Garrick R, Klistorner A. Transsynaptic retinal degeneration in optic neuropathies: optical coherence tomography study. Invest Ophthalmol Vis Sci 2012; 53: 1271-1275.

75. Iñigo Gabilondo, Elena H Martínez-Lapiscina, Eloy MartínezHeras, Elena Fraga-Pumar, Sara Llufriu, et al. Trans-synaptic axonal degeneration in the visual pathway in multiple sclerosis. Ann Neurol 2014; 75: 98-107.

76. Oberwahrenbrock T, Traber GL, Lukas S, Gabilondo I, Nolan $\mathrm{R}$, Songster C, et al. Multicenter reliability of semiautomatic retinal layer segmentation using OCT. Neurol Neuroimmunol Neuroinflamm 2018; 5: e449.

77. Keltner JL, Cello KE, Balcer LJ, Calabresi PA, Markowitz CE, Werner JS. Stratus OCT quality control in two multi-centre multiple sclerosis clinical trials. Neuro-ophthalmology 2011; 35: 57-64.

78. Cruz-Herranz A, Balk LJ, Oberwahrenbrock T, Saidha S, Martinez-Lapiscina EH, Lagreze WA, et al. The APOSTEL recommendations for reporting quantitative optical coherence tomography studies. Neurology 2016; 86: 2303-2309.

79. Schippling S, Balk LJ, Costello F, Albrecht P, Balcer L, Calabresi PA, et al. Quality control for retinal OCT in multiple sclerosis: validation of the OSCAR-IB criteria. Mult Scler 2015; 21: 163-170.

80. Heesen C, Haase R, Melzig S, Poettgen J, Berghoff M, Paul F, et al. Perceptions on the value of bodily functions in multiple sclerosis. Acta Neurol Scand 2018; 137: 356-362.

81. Gehr S, Kaiser T, Kreutz R, Ludwig WD, Paul F. Suggestions for improving the design of clinical trials in multiple sclerosisresults of a systematic analysis of completed phase III trials. EPMA J 2019; 10: 425-436.

\section{Clinical Practice Guidelines}

Clinical Practice Guidelines must include a short abstract. There should be an Introduction section addressing the objective in producing the guideline, what the guideline is about and who will benefit from the guideline. It should describe the population, conditions, health care setting and clinical management/diagnostic test. Authors should adequately describe the methods used to collect and analyze evidence, recommendations and validation. If it is adapted, authors should include the source, how, and why it is adapted? The guidelines should include not more than 50 references, 2-4 illustrations/tables, and an algorithm. 